Article

\title{
Structural Transformations of Hydrolysates Obtained from Ti-, Zr-, and Ti, Zr-Solutions Used for Clay Pillaring: Towards Understanding of the Mixed Pillars Nature
}

\author{
Krzysztof Bahranowski ${ }^{1}{ }^{1 *}$, Agnieszka Klimek ${ }^{1}$, Adam Gaweł ${ }^{1}$, Katarzyna Górniak ${ }^{1}$, \\ Alicja Michalik ${ }^{2}$ and Ewa Serwicka-Bahranowska ${ }^{2}$ D \\ 1 Faculty of Geology, Geophysics and Environmental Protection, AGH University of Science and Technology, \\ al. Mickiewicza 30, 30-059 Krakow, Poland; agaklimek@o2.pl (A.K.); agawel@agh.edu.pl (A.G.); \\ gorniak@agh.edu.pl (K.G.) \\ 2 Jerzy Haber Institute of Catalysis and Surface Chemistry, Niezapominajek 8, 30-239 Krakow, Poland; \\ ncmichal@cyf-kr.edu.pl (A.M.); ncserwic@cyf-kr.edu.pl (E.S.-B.) \\ * Correspondence: bahr@agh.edu.pl; Tel.: +48-12-617-2379
}

Received: 3 December 2018; Accepted: 21 December 2018; Published: 24 December 2018

\begin{abstract}
Structural characteristics of hydrolysates formed from the aqueous $\mathrm{Ti}-, \mathrm{Zr}-$, and $\mathrm{Ti}$, $\mathrm{Zr}$-pillaring solutions prepared from inorganic precursors $\left(\mathrm{TiCl}_{4}\right.$ and $\left.\mathrm{ZrOCl}_{2}\right)$, was investigated and compared with that of precipitates obtained from the same solutions after a slight alkalization of $\mathrm{pH}$ to the values reported for the conditions of clay pillaring. The materials were recovered by lyophilization and subsequently subjected to calcination at 500,800 and $1000{ }^{\circ} \mathrm{C}$. Of special interest was the effect of $\mathrm{pH}$ on the possible formation of mixed Ti, $\mathrm{Zr}$-oxide species. Powder X-ray diffraction (XRD), Raman spectroscopy and scanning electron microscope/energy dispersive spectrometer (SEM/EDS) analysis showed that even a relatively moderate alteration of $\mathrm{pH}$ in $\mathrm{Ti}-, \mathrm{Zr}-$, or $\mathrm{Ti}$, $\mathrm{Zr}$-precursor solutions caused substantial changes in the outcome of hydrolytic transformations, manifested by different phase and/or chemical composition of the resulting hydrolysates. Analysis of thermal evolution of hydrolysates showed that alkalization facilitated the transformation of anatase into rutile in materials obtained from Ti-pillaring solution, but retarded tetragonal to monoclinic zirconia conversion in samples derived from Zr-pillaring agent. The most striking effect was observed for the mixed Ti, Zr-pillaring solution, where an increase of $\mathrm{pH}$ enabled the formation of zirconium titanate as the only crystalline phase, rather than a multiphase mixture of anatase, monoclinic zirconia and zirconium titanate obtained from the more acidic precursor. The finding supports the model of mixed Ti-O-Zr network in props generated in Ti, Zr-pillared montmorillonites.
\end{abstract}

Keywords: hydrolysis; titania; zirconia; zirconium titanate; pillared clays

\section{Introduction}

Pillaring of clays is a process in which common interlayer hydrated cations compensating the layer charge are exchanged with large hydrated inorganic polymeric oxy-hydroxy cationic species which prop open the silicate layers [1]. Upon high temperature treatment, the oligomers are transformed into oxide nanoparticles and link permanently the neighboring layers. The resulting solids, referred to as pillared interlayered clays (PILCs), are characterized by large surface area, high pore volume and pore size tunable from micropore to low mesopore range. In addition, appropriate modification of the chemical nature of pillars enables control of the materials acid-base and redox properties. In recent work, we have shown that pillaring of montmorillonite clay with mixed [Ti, Zr]-pillaring solution 
yielded material of unique structural, textural and surface acid-base properties, differing from those of reference Ti-PILC and Zr-PILC structures [2]. As a result, the [Ti, Zr]-PILC displayed superior properties when used as support for $\mathrm{Pd}$ and/or Cr catalysts for the destruction of chlorinated volatile organic compounds [3]. The study suggested that pillars in [Ti, Zr]-PILC consisted of nano-clusters of a quasi-amorphous Ti-Zr mixed oxide, rather than separate titania and zirconia pillars, of short-range order similar to that of zirconium titanate phase. However, it should be noted that there is a lack of a general agreement as to the nature of props formed from pillaring agents containing both the $\mathrm{Ti}$ and the $\mathrm{Zr}$ precursor. Thus, although Das, et al. [4] reached a similar conclusion as to the binary nature of Ti-Zr pillars, some other reports discussed the results of smectite pillaring with mixed Ti-Zr pillaring solutions in terms of separate $\mathrm{TiO}_{2}$ and $\mathrm{ZrO}_{2}$ pillars $[5,6]$.

The nature of the final form of intercalated species depends on the hydrolytic transformations occurring in pillaring solutions, which, in turn, are $\mathrm{pH}$ dependent, since an increase of $\mathrm{pH}$ facilitates the hydrolysis [7]. We have reported that during preparation of mixed component [Ti, Zr]-PILC and reference one-component Ti-PILC, Zr-PILC, after mixing of pillaring solutions with the aqueous suspension of clay, the final $\mathrm{pH}$ of the suspensions stabilized at a value higher than that of the corresponding pillaring agent, i.e., it increased from from 0.1 to 1.2 for Ti-based system, from 1.0 to 1.5 for Zr-based system, and from 0.6 to 1.2 for Ti, Zr-based system, [2]. Hydrolytic transformations occurring in the pillaring solutions upon $\mathrm{pH}$ modification are bound to have an impact on the final effect of pillaring therefore, we decided to get insight into the relation between the $\mathrm{pH}$ of pillaring agents and the nature of hydrolysates obtained from such precursors. To achieve this aim, in the present work, we investigated the character of precipitates formed from the as received $\mathrm{Ti}-, \mathrm{Zr}-$, and $\mathrm{Ti}$, $\mathrm{Zr}$-pillaring agents (lower $\mathrm{pH}$ values), and compared their characteristics with those of precipitates obtained from the same solutions after adjustment of $\mathrm{pH}$ to the values observed during pillaring. Of special interest was the effect of $\mathrm{pH}$ on the possible formation of mixed [Ti, $\mathrm{Zr}$ ] oxide species, because an understanding of the nature of pillars in Ti, Zr-pillared clays is of key importance for the interpretation of their catalytic, photocatalytic and sorption properties. However, the significance of this study is not limited to the chemistry of pillared clays, since zirconium titanate-based systems are not only fascinating catalytic materials in their own right, but find also use in advanced microwave technology, optical devices, and as ceramic insulators [8-12].

\section{Materials and Methods}

\subsection{Materials}

In the present work $\mathrm{TiCl}_{4}$ (Aldrich, pure, $\geq 98 \%$, St. Louis, $\mathrm{MO}, \mathrm{USA}$ ) and $\mathrm{ZrOCl}_{2} \cdot 8 \mathrm{H}_{2} \mathrm{O}$ (Fluka, analytical grade, Munich, Germany) were used for the preparation of $\mathrm{Ti}, \mathrm{Zr}$ or [Ti, $\mathrm{Zr}$-containing solutions, following the preparative procedure of pillaring agents described in [2]. Briefly, Ti-pillaring solution was prepared by theslow addition of $4.5 \mathrm{~mL} \mathrm{TiCl}_{4}$ to $1.25 \mathrm{~mL} 6 \mathrm{M} \mathrm{HCl}$ under vigorous stirring, followed by dilution with $50 \mathrm{~mL}$ distilled water. The stirring continued at room temperature for $3 \mathrm{~h}$. The $\mathrm{pH}$ value of the resulting clear solution was 0.1 . Zr-pillaring solution was obtained by dissolving $13.5 \mathrm{~g} \mathrm{ZrOCl}_{2} \cdot 8 \mathrm{H}_{2} \mathrm{O}$ in $333 \mathrm{~mL}$ distilled water and stirring for $1 \mathrm{~h}$ at room temperature. The $\mathrm{pH}$ value of the clear solution was 1.0. Mixed [Ti, $\mathrm{Zr}$ ] solution was prepared by the dropwise addition of Ti-pillaring agent to the Zr-containing solution, to obtain 1:1 molar ratio of Ti and Zr. After $1 \mathrm{~h}$ stirring at room temperature the $\mathrm{pH}$ of the clear solution was 0.6 .

Two series of experiments were carried out with the prepared pillaring solutions. One involved obtaining the precipitates from the freshly prepared $\mathrm{Ti}-, \mathrm{Zr}-$, and $\mathrm{Ti}, \mathrm{Zr}$-pillaring agents by lyophilization. These samples are denoted Ti-0.1, Zr-1.0, and Ti, Zr-0.6 (numerical indices correspond to the natural $\mathrm{pH}$ of the solutions), and after $3 \mathrm{~h}$ calcination as Ti-0.1-temp, Zr-1.0-temp, and Ti, Zr-0.6-temp, where temp is the calcination temperature $\left(500,800\right.$ or $\left.1000{ }^{\circ} \mathrm{C}\right)$. The other series was prepared from the same pillaring agents, but prior to lyophilization their $\mathrm{pH}$ was adjusted with $0.1 \mathrm{M} \mathrm{NH}_{3}$ aq to the values registered after mixing of the pillaring solutions with the suspension of montmorillonite. Thus, obtained 
hydrolysates are referred to as Ti-1.2, $\mathrm{Zr}-1.5$, and $\mathrm{Ti}, \mathrm{Zr}-1.2$ (numerical indices correspond to the ammonia adjusted $\mathrm{pH}$ of the solutions), and after $3 \mathrm{~h}$ calcination as Ti-1.2-temp, $\mathrm{Zr}$-1.5-temp, and Ti, $\mathrm{Zr}$-1.2-temp, where temp is the calcination temperature $\left(500,800\right.$ or $\left.1000{ }^{\circ} \mathrm{C}\right)$.

\subsection{Methods}

Powder X-ray diffraction (XRD) patterns were recorded with Rigaku SmartLab diffractometer (Neu-Isenburg, Tokyo, Japan) under the following conditions: Graphite-monochromatized CuK $\alpha$ radiation, operating voltage $45 \mathrm{kV}$, current $200 \mathrm{~mA}$, step size $0.05^{\circ}$ and counting time $1 \mathrm{~s} /$ step.

Raman spectra were collected with a DXR Raman microscope (Thermo Scientific, Waltham, MA, USA) using $532 \mathrm{~nm}$ excitation laser wavelength, power level $6 \mathrm{~mW}$ and spectral resolution $2 \mathrm{~cm}^{-1}$.

Field emission scanning electron microscopy (FESEM) studies were carried out for the uncoated samples with the use of an FEI Quanta 200 FEG SEM (Hillsboro, OR, USA) equipped with a secondary electron (SE) and back-scattered electron (BSE) detectors. Energy dispersive spectrometer (EDS, FEI Quanta, Hillsboro, OR, USA) was employed to monitor variations of chemical composition in mixed $\mathrm{Ti}, \mathrm{Zr}$ phases, using polished specimens of samples embedded in epoxy resin.

\section{Results and Discussion}

\subsection{Hydrolysates Formed fromTi-Pillaring Solution}

The XRD patterns of precipitates obtained by lyophilization of the as received Ti-pillaring solution $(\mathrm{pH}=0.1)$ are presented in Figure $1 \mathrm{a}$, while Figure 1b shows XRD diagrams of lyophilized precipitates obtained from solutions whose $\mathrm{pH}$ has been adjusted to 1.2, the value observed upon preparation of Ti-pillared montmorillonite. The XRD pattern of the as received lyophilized Ti-0.1 sample shows only a broad reflection around $2 \Theta \approx 9.3^{\circ}$, corresponding to ca. $9.5 \AA$ interplanar distance, and an even broader, low intensity bump centered around $2 \Theta \approx 25^{\circ}(\mathrm{d} \approx 3.5 \AA$ ), which points to the chiefly amorphous character of the solid components. The low angle reflection may be taken as an indication that part of the amorphous solid tends to form a layered structure, e.g., related to the lepidocrocite-type protonated titanate [13]. The feature with $\mathrm{d} \approx 3.5 \AA$ may be attributed to an amorphous phase from which a titania polymorph is going to nucleate. After calcination of the precipitate at $500{ }^{\circ} \mathrm{C}$ (sample Ti-0.1-500) the XRD pattern shows a set of intense reflections characteristic of crystalline anatase (A), accompanied by trace amounts of rutile (R). Material calcined at $800{ }^{\circ} \mathrm{C}$ contains a higher relative share of rutile, and after heat treatment at $1000^{\circ} \mathrm{C}$, rutile is the only detected crystalline $\mathrm{TiO}_{2}$ phase.

The XRD pattern of Ti-1.2 precipitate obtained from pillaring solution whose $\mathrm{pH}$ was raised with $\mathrm{NH}_{3}$ aq to the value observed during Ti-PILC formation, shows that some ammonium chloride has been formed in the process, as indicated by the set of sharp reflections characteristic of this salt. The broad reflection at $2 \Theta \approx 7^{\circ}(\mathrm{d} \approx 12.5 \AA)$ indicates that also here an amorphized layered structure is formed, probably of similar nature as in Ti-0.1, but with higher content of water in the interlayer [13]. The titania-related phase, although still poorly crystalline, is better defined than in the case of Ti- 0.1 sample. The most pronounced reflection around $2 \Theta \approx 25^{\circ}(\mathrm{d} \approx 3.5 \AA)$ and the reflection at $2 \Theta \approx$ $37.5^{\circ}(\mathrm{d} \approx 2.39 \AA)$ suggests nucleation of anatase and/or brookite. A contribution of the latter may be inferred from the faint reflection around $2 \Theta \approx 31^{\circ}(\mathrm{d} \approx 2.88 \AA)$ diagnostic of brookite polymorph. XRD pattern of Ti-1.2-500 sample shows that after calcination at $500{ }^{\circ} \mathrm{C}$ the material contains predominantly anatase, but transformation to rutile is more advanced than in the Ti-0.1-500 counterpart. Rutile is the only crystalline phase found in samples calcined at 800 and $1000{ }^{\circ} \mathrm{C}$. Thus, a comparison of the thermal evolution of both precipitates shows that transformation of anatase into rutile is slightly facilitated in the material obtained from alkalized pillaring solution. 

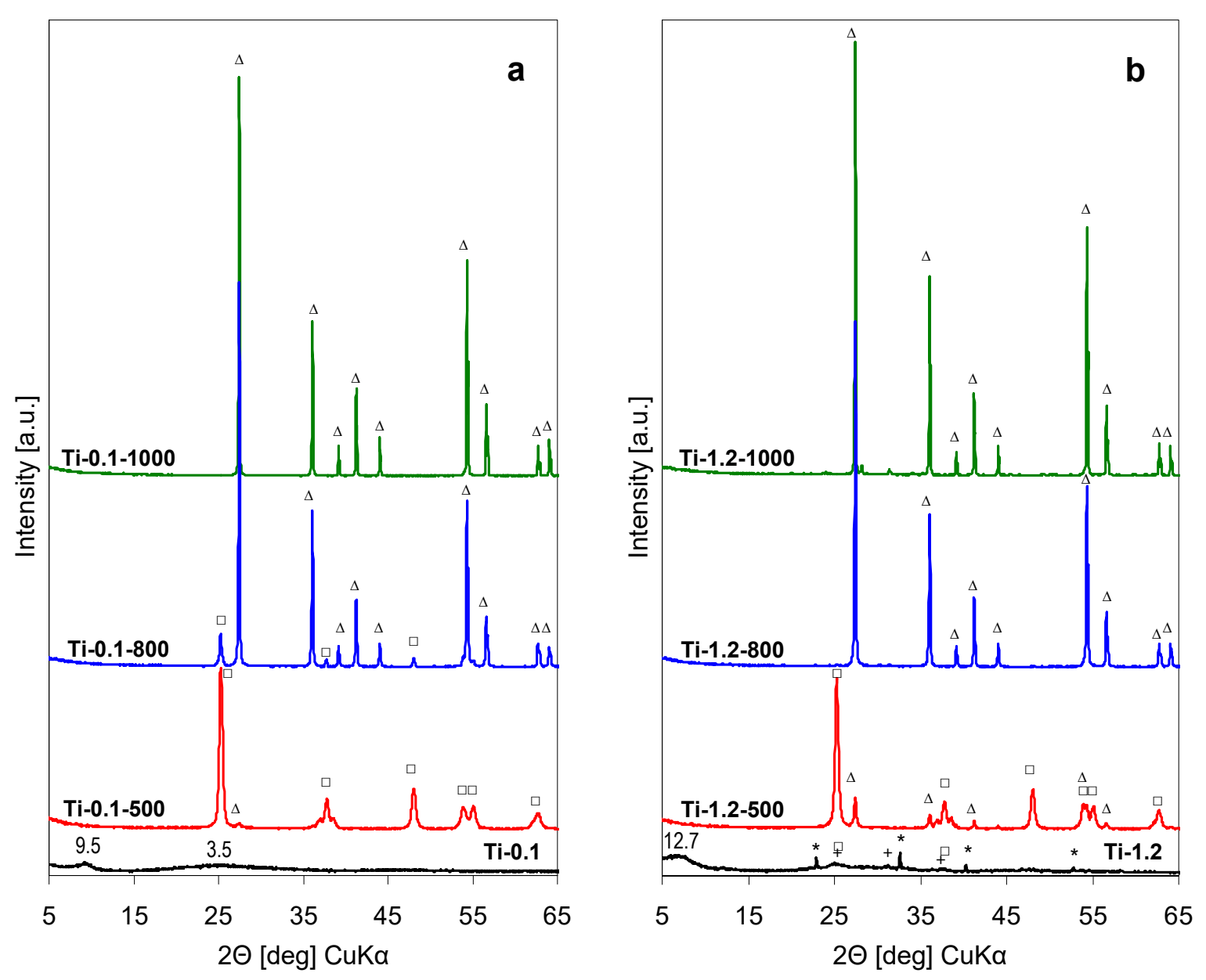

Figure 1. Powder X-ray diffraction (XRD) patterns illustrating the effect of thermal treatment on hydrolysates obtained by lyophilization of Ti-pillaring solution: (a) As received at $\mathrm{pH}=0.1$, (b) after $\mathrm{pH}$ adjustment to 1.2 ( $\square$ anatase, $\Delta$ rutile, + brookite, ${ }^{*} \mathrm{NH}_{4} \mathrm{Cl}$ ).

Structure of the precipitates was also studied with Raman spectroscopy, more powerful than XRD for detecting short range order in amorphous nanodomains [14]. Therefore, Raman analysis was expected to shed more light on the structure of the thermally untreated Ti-0.1 and Ti-1.2 precipitates, essentially amorphous from the XRD point of view. Various titania polymorphs and layered titanates are known to exhibit characteristic Raman spectra, and the present interpretation of the data follows previous assignments [15-18]. The Raman spectra monitoring thermal evolution of Ti-0.1 precipitate, are shown in Figure 2a, those obtained for the Ti-1.2 series, in Figure 2b.

The Raman spectrum of the lyophylized Ti-0.1 sample, shown in Figure 2a, displays several ill-defined broad bands, centered around 150, 260, 440,670,930 $\mathrm{cm}^{-1}$. All, except the first one, may be considered as envelopes of broadened bands stemming from amorphized lepidocrocite-type titanate phase [18], whose presence has been suggested on the base of the XRD pattern (Figure 1a). The feature around $150 \mathrm{~cm}^{-1}$ appears in the range where the most intense bands of anatase or brookite appear, and is attributed to the amorphous titania structures responsible for the broad XRD bump centered at $\mathrm{d}=3.5 \AA$ in Figure $1 \mathrm{a}$. 

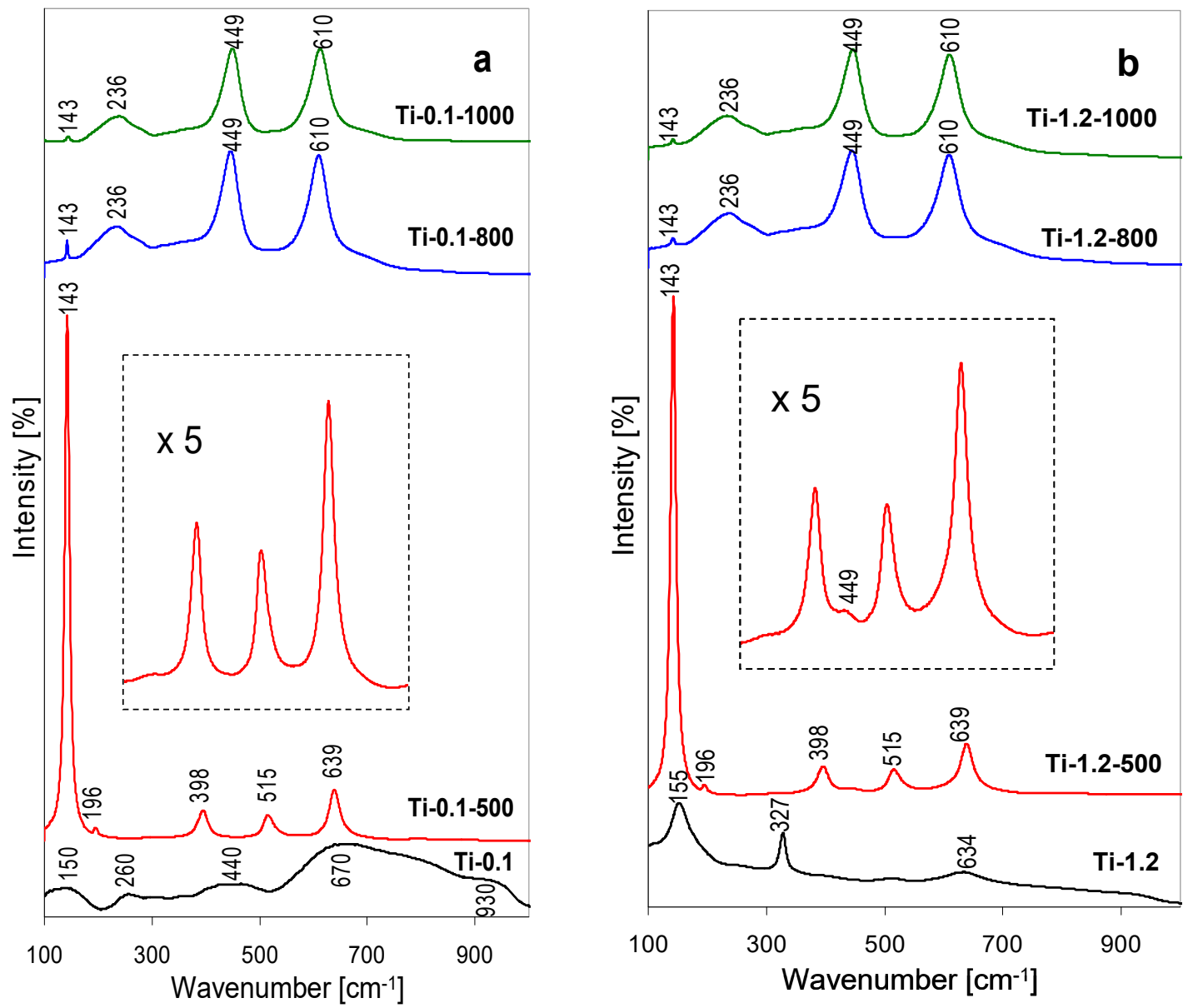

Figure 2. Raman spectra illustrating the effect of thermal treatment on hydrolysates obtained by lyophilization of Ti-pillaring solution: (a) As received at $\mathrm{pH}=0.1$, (b) after $\mathrm{pH}$ adjustment to 1.2.

The spectrum of Ti-1.2 precipitate, obtained from the pillaring solution after $\mathrm{pH}$ adjustment, shows better resolved features. The set of bands at 155,327 and $634 \mathrm{~cm}^{-1}$ points to the formation of poorly crystalline brookite [16,17], thus substantiating the tentative assignment derived from the XRD data. Indeed, Pottier, et al. [19] reported that $\mathrm{Ti}(\mathrm{OH})_{2}(\mathrm{Cl})_{2}\left(\mathrm{OH}_{2}\right)_{2}$ species formed during hydrolysis of $\mathrm{TiCl}_{4}$, in strongly acidic medium enriched with chloride ions, initially tend to form the brookite phase. In this spectral range the dominant band of $\mathrm{NH}_{4} \mathrm{Cl}$ appears around $180 \mathrm{~cm}^{-1}$, but the amount of impurity is too small to make an impact on the recorded Raman spectrum. The spectra obtained for both series of thermally treated samples essentially agree with the conclusions drawn from XRD examination. Thus, the spectra of samples after calcination at $500{ }^{\circ} \mathrm{C}$ are dominated by the bands at $143,196,398,515$ and $639 \mathrm{~cm}^{-1}$ characteristics of anatase [15]. The presence of rutile admixture can be detected in Ti-1.2-500 as a shoulder at $449 \mathrm{~cm}^{-1}$, clearly visible in the magnified part of the spectrum in Figure 2b. The trace of rutile indicated by XRD in Ti-0.1-500 is apparently too small to reveal its presence in the Raman spectrum (magnified fragment in Figure 2a). The spectra of samples calcined at higher temperatures are dominated by the bands typical of rutile, i.e., a weak one at $143 \mathrm{~cm}^{-1}$ and three strong features at 236, 449 and $610 \mathrm{~cm}^{-1}$, which agrees with the XRD analysis pointing to the occurrence of anatase to rutile phase transformation [15]. The presence of some anatase remnants, revealed by XRD in sample Ti-0.1-800, may be inferred from the slightly higher, than in other samples, intensity of the $143 \mathrm{~cm}^{-1}$ band, which indicates a contribution from the coincident most intense band of anatase (Figure 2a). 
SEM images of samples Ti-0.1-1000 and Ti-1.2-1000 presented in Figure 3a,d, respectively, show that after calcination at $1000{ }^{\circ} \mathrm{C}$ the morphology of both materials is quite similar, with particles size being, in general, $\leq 0.5 \mu \mathrm{m}$.
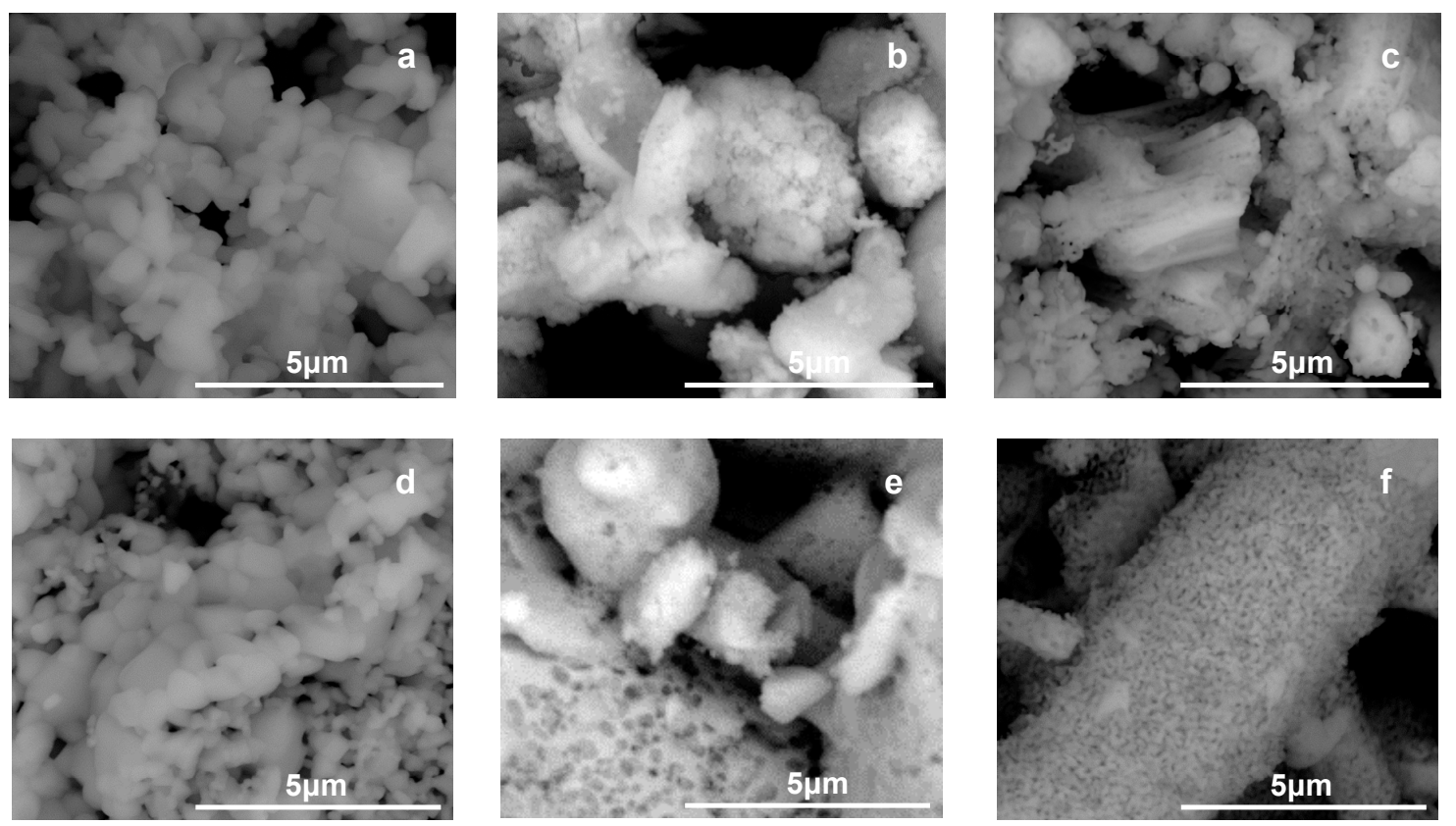

Figure 3. Field Emission Scanning Electron Microscope (FESEM) images of: (a) Ti-0.1-1000, (b) Zr-1.0-1000, (c) Ti, Zr-0.6-1000, (d) Ti-1.2-1000, (e) Zr-1.5-1000, (f) Ti, Zr-1.2-1000.

\subsection{Hydrolysates Formed from Zr-Pillaring Solution}

Figure $4 \mathrm{a}$ shows the XRD patterns of precipitates obtained from the as received Zr-pillaring solution $(\mathrm{pH}=1.0)$, Figure $4 \mathrm{~b}$ gathers $\mathrm{XRD}$ data obtained for the solids prepared from the $\mathrm{Zr}$-pillaring agent whose $\mathrm{pH}$ has been raised to 1.5, the value observed during Zr-PILC synthesis. The XRD pattern of the as received lyophilized $\mathrm{Zr}-1.0$ sample appears essentially amorphous. It is dominated by a broad reflection around $2 \Theta \approx 8^{\circ}$, corresponding to ca. $11 \AA$ interplanar distance. The most intense reflections of various $\mathrm{ZrOCl}_{2}$ hydrates appear in the $7^{\circ}<2 \Theta<8.6^{\circ}$ range (e.g., $\mathrm{ZrOCl}_{2} \cdot 8 \mathrm{H}_{2} \mathrm{O}$, JCPDS 00-032-1498, $\mathrm{ZrOCl}_{2} \cdot 6 \mathrm{H}_{2} \mathrm{O}$, JCPDS 00-047-0815, $\mathrm{ZrOCl}_{2} \cdot 4 \mathrm{H}_{2} \mathrm{O}$, JCPDS 00-018-1497). Matsui and Ohgai [20], in their extensive study of $\mathrm{ZrOCl}_{2}$ hydrolysis, referred to such a product as chlorine-containing hydrous zirconia. Calcination of this precipitate at $500{ }^{\circ} \mathrm{C}$ leads to crystallization of tetragonal $\mathrm{ZrO}_{2}$ polymorph $\left(t-\mathrm{ZrO}_{2}\right)$. In addition, in the XRD pattern of $\mathrm{Zr}-0.1-500$ a trace of peak at $2 \Theta=$ $28.2^{\circ}(\mathrm{d}=3.162 \AA)$, corresponding to the most intense reflection of the monoclinic zirconia $\left(m-\mathrm{ZrO}_{2}\right)$, is observed, which shows that a small degree of transformation of the metastable $t-\mathrm{ZrO}_{2}$ to the stable $m-\mathrm{ZrO}_{2}$ has already occurred. After calcination at $800{ }^{\circ} \mathrm{C}$ the transformation is almost complete and the material is composed predominantly of $m-\mathrm{ZrO}_{2}$, with only a trace of unreacted tetragonal phase, manifested by the remainder of the most intense reflection of $t-\mathrm{ZrO}_{2}$ at $2 \Theta=30.2^{\circ}(\mathrm{d}=2.957 \AA)$. Sample calcined at $1000{ }^{\circ} \mathrm{C}$ contains only $m-\mathrm{ZrO}_{2}$.

The XRD pattern of $\mathrm{Zr}-1.5$ precipitate obtained from pillaring solution whose $\mathrm{pH}$ was adjusted to 1.5 with ammonia, shows that, similarly as in the case of Ti-1.2, some ammonium chloride has been formed. Otherwise, the diffractogram displays broad reflection at $2 \Theta \approx 7.5^{\circ}(\mathrm{d} \approx 11.7 \AA)$, together with a broad bump centered around $2 \Theta \approx 25^{\circ}(\mathrm{d} \approx 3.5 \AA)$, i.e. at a lower angle than that expected for amorphous $\mathrm{ZrO}_{2}$ (broad envelope around $2 \Theta=30^{\circ} \mathrm{C}$ [21]). This shows that, even after an increase of $\mathrm{pH}$, the precipitate bears feature of chlorine-containing hydrous zirconia [20] rather than of an amorphous precursor of $t-\mathrm{ZrO}_{2}$. The latter phase appears as the only crystalline product after calcination at $500{ }^{\circ} \mathrm{C}$. In $\mathrm{Zr}-1.5-800$ the transformation of most of the tetragonal phase to $m-\mathrm{ZrO}{ }_{2}$ is 
visible, although the intensity of the remaining $2 \Theta=30.2^{\circ}$ reflection of $t-\mathrm{ZrO}_{2}$ is stronger than in the $\mathrm{Zr}-1.0-800$ counterpart. Its very weak trace persists even in $\mathrm{Zr}-1.5-1000$, although monoclinic zirconia is the predominant crystalline phase found in this material.
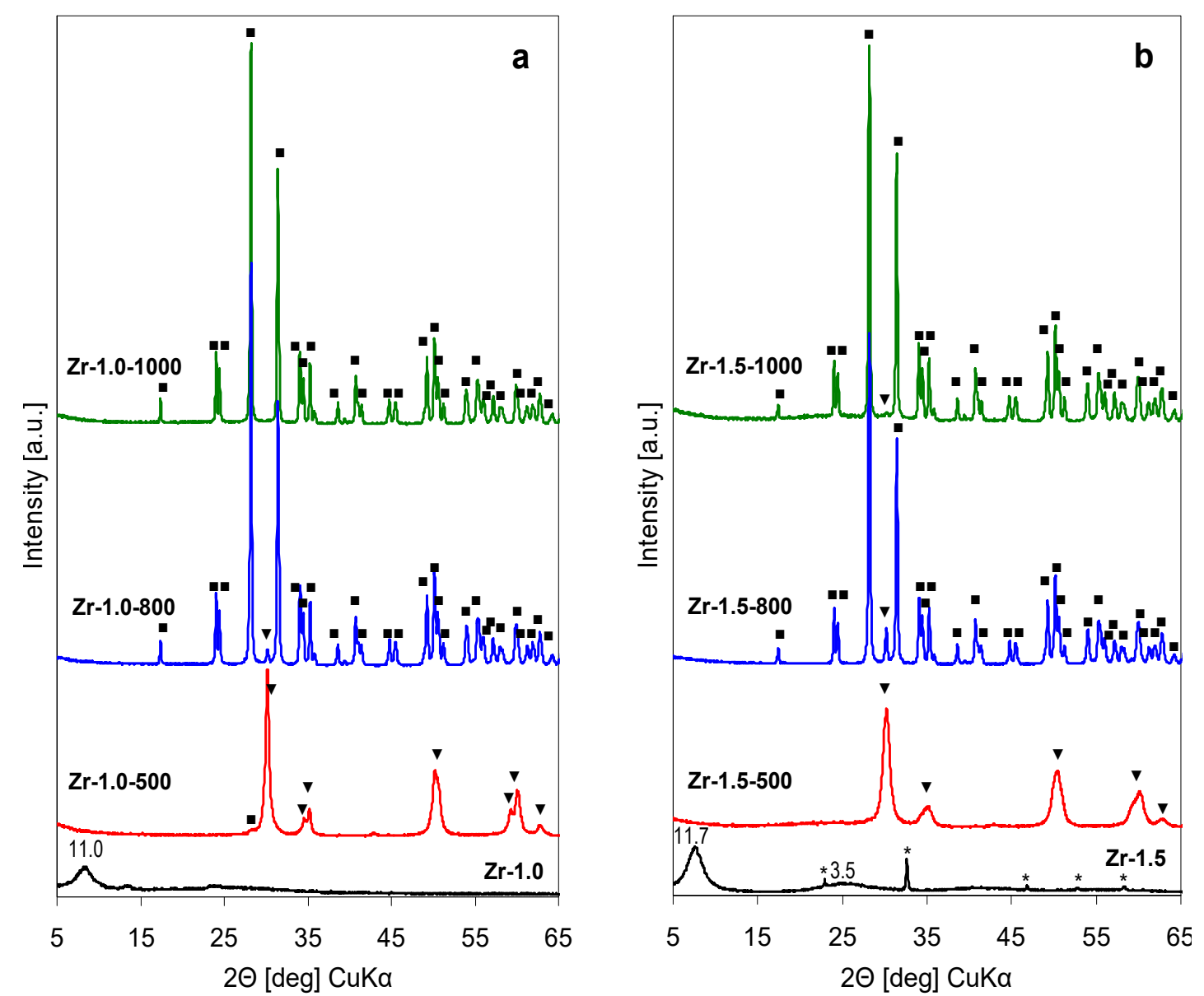

Figure 4. XRD patterns illustrating the effect of thermal treatment on hydrolysates obtained by lyophilization of $\mathrm{Zr}$ - pillaring solution: (a) As received at $\mathrm{pH}=1.0$, (b) after $\mathrm{pH}$ adjustment to 1.5 $\left(\nabla \mathrm{t}-\mathrm{ZrO}_{2}, \mathbf{\square} m-\mathrm{ZrO}_{2},{ }^{*} \mathrm{NH}_{4} \mathrm{Cl}\right)$.

The Raman spectra of the thermal evolution of Zr-1.0 sample are shown in Figure 5a, those recorded for the Zr-1.5 series, in Figure 5b. The spectra of Zr-1.0 and Zr-1.5 are quite similar and display several broad bands, centered around 130, 230, 410 and $520 \mathrm{~cm}^{-1}$. Similarly, as in the case of Ti-1.2, no bands attributable to $\mathrm{NH}_{4} \mathrm{Cl}$ impurity are visible. The observed features are similar to those reported previously for non-crystalline solids obtained from freshly hydrolyzed $\mathrm{ZrOCl}_{2}$ [22,23]. The intermediate character of Zr-1.0 and Zr-1.5 precipitates, referred to as chlorine-containing hydrous zirconia, is evidenced by the fact that the observed broad bands are different from those characteristics of $\mathrm{ZrOCl}_{2}$ hydrate precursor (460 and $590 \mathrm{~cm}^{-1}$ ) [21], but do not yet display features typical of zirconia polymorphs (see thermal evolution of Raman spectra). In contrast, the spectra of thermally treated Zr-1.0-500 and Zr-1.5-500 show well defined bands characteristic of tetragonal zirconia $\left(147,268,319,463,608,648 \mathrm{~cm}^{-1}\right)[21,24]$. In accordance with the XRD findings, the spectrum of $\mathrm{Zr}-1.0-500$ shows some low intensity features characteristic of the most intense bands of $m-\mathrm{ZrO}_{2}\left(178,190,382,475 \mathrm{~cm}^{-1}\right)$. The Raman spectra recorded for samples treated at 800 and $1000{ }^{\circ} \mathrm{C}$ are similar, and reflect the transformation of most, or all of the calcined material to monoclinic $\mathrm{ZrO}_{2}$ polymorph. In agreement with XRD analysis, small amounts of $t-\mathrm{ZrO}_{2}$ are still visible in both samples calcined at $800{ }^{\circ} \mathrm{C}$ (low intensity bands at 147 and $268 \mathrm{~cm}^{-1}$ ), albeit with higher intensity in the $\mathrm{Zr}-1.5-800$ sample. A trace of tetragonal zirconia can be still detected in the spectrum of $\mathrm{Zr}-1.5-1000$ (weak band at $268 \mathrm{~cm}^{-1}$ ) bands, thus confirming that 
alkalization of Zr-pillaring solution yields hydrolysate in which tetragonal to monoclinic zirconia transformation is retarded.
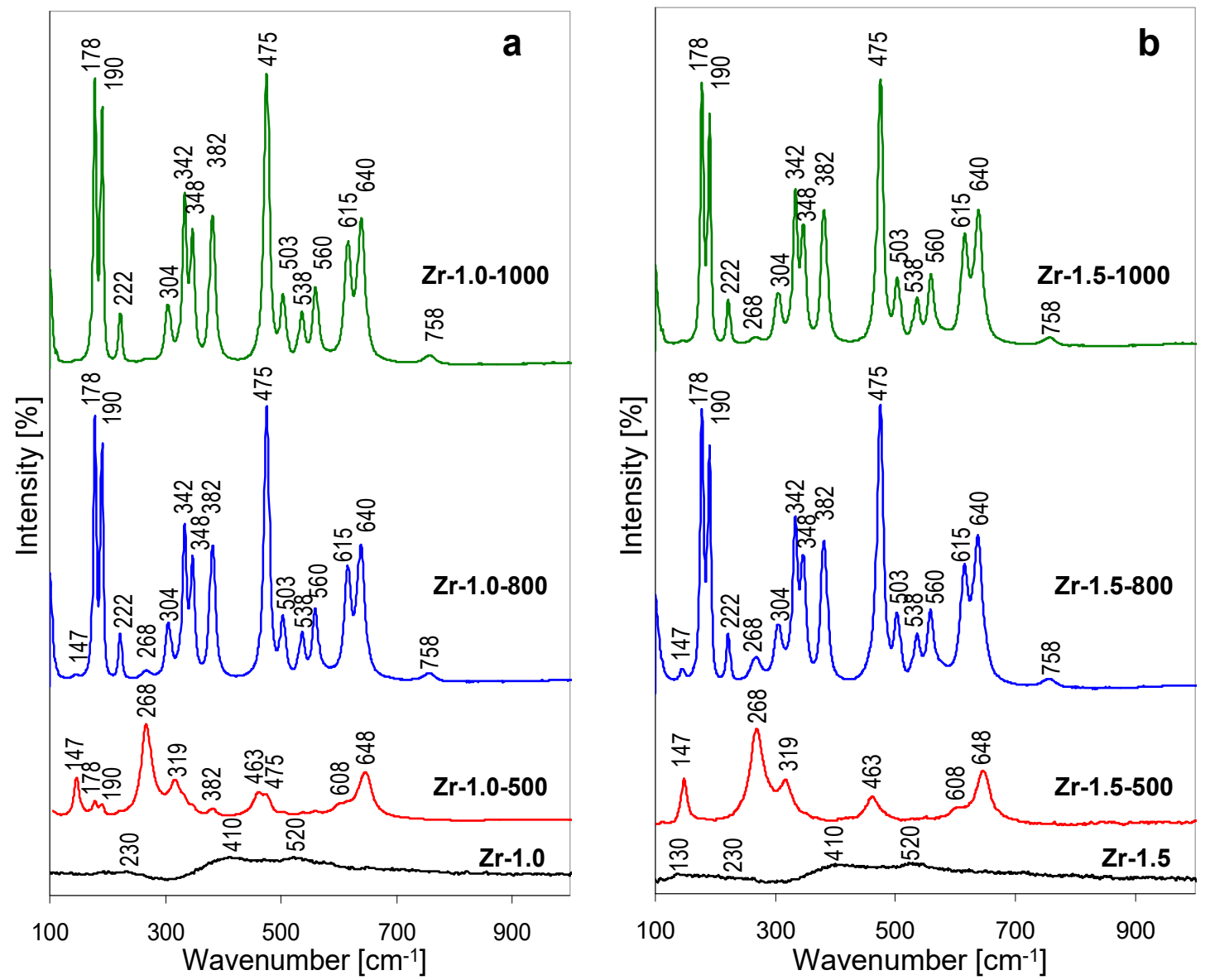

Figure 5. Raman spectra illustrating the effect of thermal treatment on hydrolysates obtained by lyophilization of $\mathrm{Zr}$-pillaring solution: (a) As received at $\mathrm{pH}=1.0$, (b) after $\mathrm{pH}$ adjustment to 1.5.

SEM images of samples Zr-0.1-1000 and Zr-1.2-1000, presented in Figure 3b,e, respectively, show that in both materials' zirconia grains consist of variously shaped agglomerates.

\subsection{Hydrolysates Formed from Ti, Zr-Pillaring Solution}

XRD patterns of precipitate recovered by lyophilization from the as received $\mathrm{Ti}, \mathrm{Zr}$-pillaring solution $(\mathrm{pH}=0.6)$ and of the products of its thermal evolution are shown in Figure 6a. Those recorded for the materials obtained from the Ti, Zr-pillaring agent after adjustment of $\mathrm{pH}$ to 1.2, i.e., the value observed during Ti, Zr-PILC synthesis, are gathered in Figure $6 \mathrm{~b}$.

The XRD pattern of lyophilized $\mathrm{Ti}, \mathrm{Zr}-0.6$ precipitate shows a set of reflexes pointing to the presence of a certain amount of variously hydrated $\mathrm{ZrOCl}_{2}$. Formation of these phases shows that in the as received $\mathrm{Ti}, \mathrm{Zr}$-pillaring solution the tendency to form mixed species, if at all present, is limited. Moreover, the zirconyl chloride phases are better defined than in the case of $\mathrm{Zr}-1.0$ precipitate obtained from the $\mathrm{Zr}$-pillaring solution, which is attributed to the slower hydrolysis of the salt in the conditions of lower $\mathrm{pH}$ characteristic for mixed pillaring agent. The peaks of zirconyl chloride hydrates overlap with a component showing a broad maximum around $2 \Theta \approx 6.0^{\circ}$, corresponding to an interplanar distance of ca. $14.7 \AA$, and an elevated background centered around $2 \Theta \approx 28^{\circ}(\mathrm{d} \approx 3.2 \AA)$, indicating formation of a quasi-amorphous layered precursor of unknown composition. XRD analysis of sample calcined at $500{ }^{\circ} \mathrm{C}$ shows that the material is multiphase, with the evident presence of anatase form of titania, monoclinic polymorph of zirconia and mixed zirconium titanate $\left(\mathrm{ZrTiO}_{4}\right)$. Moreover, in view 
of the strong overlap of XRD pattern of tetragonal zirconia with that of $\mathrm{ZrTiO}_{4}$, some contribution of the former cannot be completely excluded. The observed multiphase composition indicates that in the precipitate formed from the as received $\mathrm{Ti}, \mathrm{Zr}$-pillaring solution, there is a strong tendency to form separate $\mathrm{Zr}$ - and Ti-based phases.
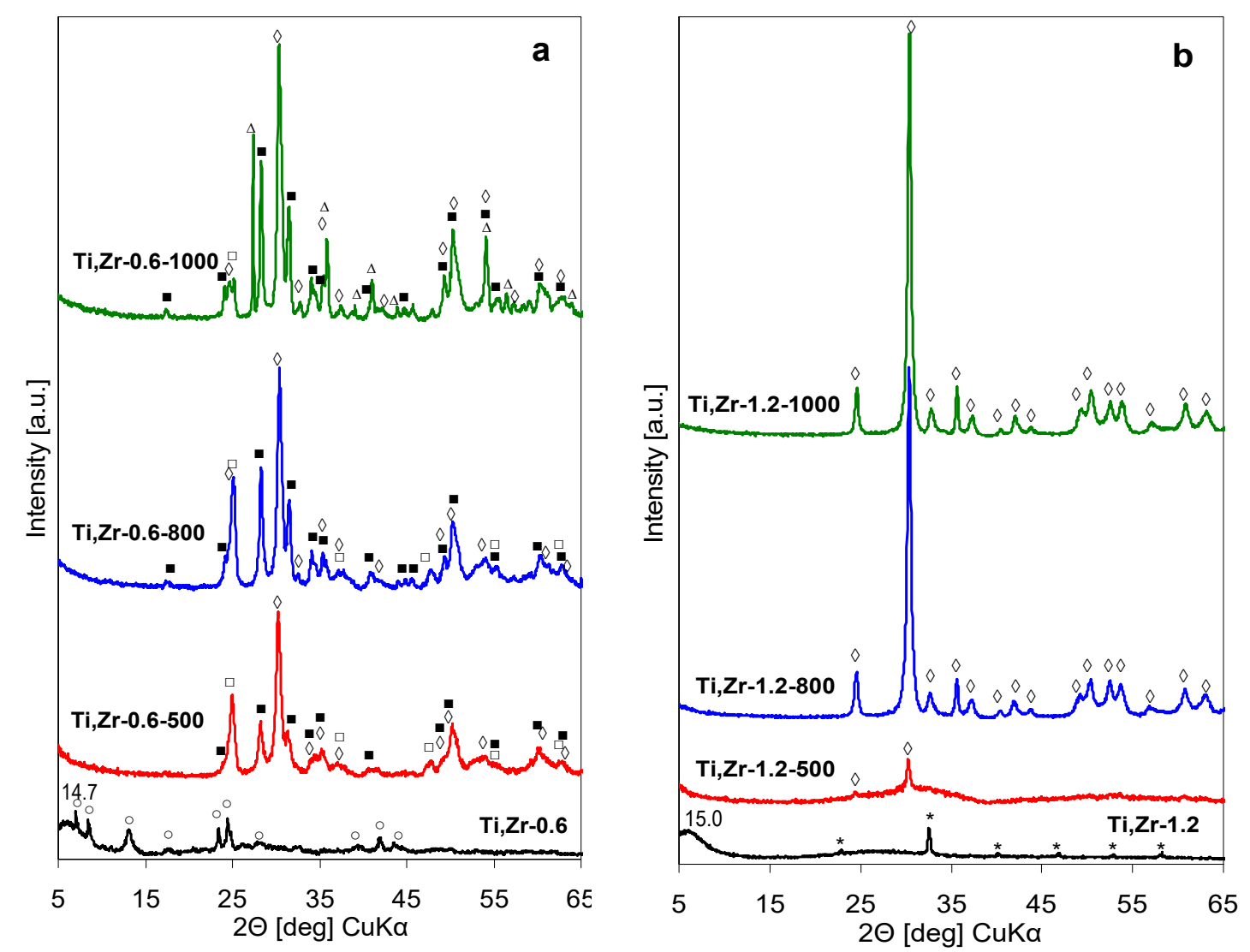

Figure 6. XRD patterns illustrating the effect of thermal treatment on hydrolysates obtained by lyophilization of Ti, $\mathrm{Zr}$ - pillaring solution: (a) As received at $\mathrm{pH}=0.6$, (b) after $\mathrm{pH}$ adjustment to 1.2 $\left(\bigcirc \mathrm{ZrOCl}_{2} \cdot x \mathrm{H}_{2} \mathrm{O}, \mathbf{\square} m-\mathrm{ZrO}_{2}, \square\right.$ anatase, $\diamond \mathrm{TiZrO}_{4}, \Delta$ rutile, $\left.{ }^{*} \mathrm{NH}_{4} \mathrm{Cl}\right)$.

Calcination at 800 and $1000{ }^{\circ} \mathrm{C}$ temperatures confirms this observation, as separate phases appear to evolve independently (Figure 6a). Thus, the phase composition of the sample calcined at $800{ }^{\circ} \mathrm{C}$ is the same as after calcination at $500{ }^{\circ} \mathrm{C}$, except for all phases showing better resolved reflections, consistent with their higher crystallinity. Noteworthy, in the case of material obtained from Zr-pillaring solution, the monoclinic form of $\mathrm{ZrO}_{2}$ is clearly visible only after calcination at $\geq 800{ }^{\circ} \mathrm{C}$ (see Section 3.2), while in the material obtained from $\mathrm{Ti}, \mathrm{Zr}$ pillaring agent, $m-\mathrm{ZrO}_{2}$ appears already at $500{ }^{\circ} \mathrm{C}$. Teng, et al. [25] reported that partial isomorphous substitution of $\mathrm{Zr}$ with $\mathrm{Ti}$ facilitates tetragonal to monoclinic polymorph transition. Indeed, in the present study a shift in the position of (-111) reflection of $m-\mathrm{ZrO}_{2}$ (indexed according to JCPDS 37-1484) to higher $2 \Theta$ values, with respect to monoclinic zirconia obtained from Zr-pillaring solution, is observed (Figure 7a). This points to a decrease of the corresponding interplanar distance and is consistent with a degree of substitution of large $\mathrm{Zr}^{4+}$ cations (ionic radius $0.72 \AA$ ) with smaller $\mathrm{Ti}^{4+}$ species (ionic radius $0.605 \AA$ ). After calcination at $1000{ }^{\circ} \mathrm{C}$, the transformation of anatase to rutile is observed, albeit not complete, as some anatase can still be detected. This shows that phase transformation in titania obtained from mixed Ti, Zr-pillaring solution occurs at temperature ca. $200{ }^{\circ} \mathrm{C}$ higher than in the sample prepared from Ti-pillaring agent (see Section 3.1). Also, here the likely explanation is that in anatase formed from Ti, Zr-pillaring solution some Ti is substituted with $\mathrm{Zr}$, the effect known to slow down the anatase to rutile transformation [25-28]. Indeed, the (101) reflection of anatase (indexed according to JCPDS 21-1272), observed in the sample obtained from 
mixed Ti, Zr-pillaring solution, is shifted to slightly lower $2 \Theta$ value (Figure $7 \mathrm{~b}$ ), which is consistent with the partial replacement of $\mathrm{Ti}^{4+}$ with larger $\mathrm{Zr}^{4+}$ ions.
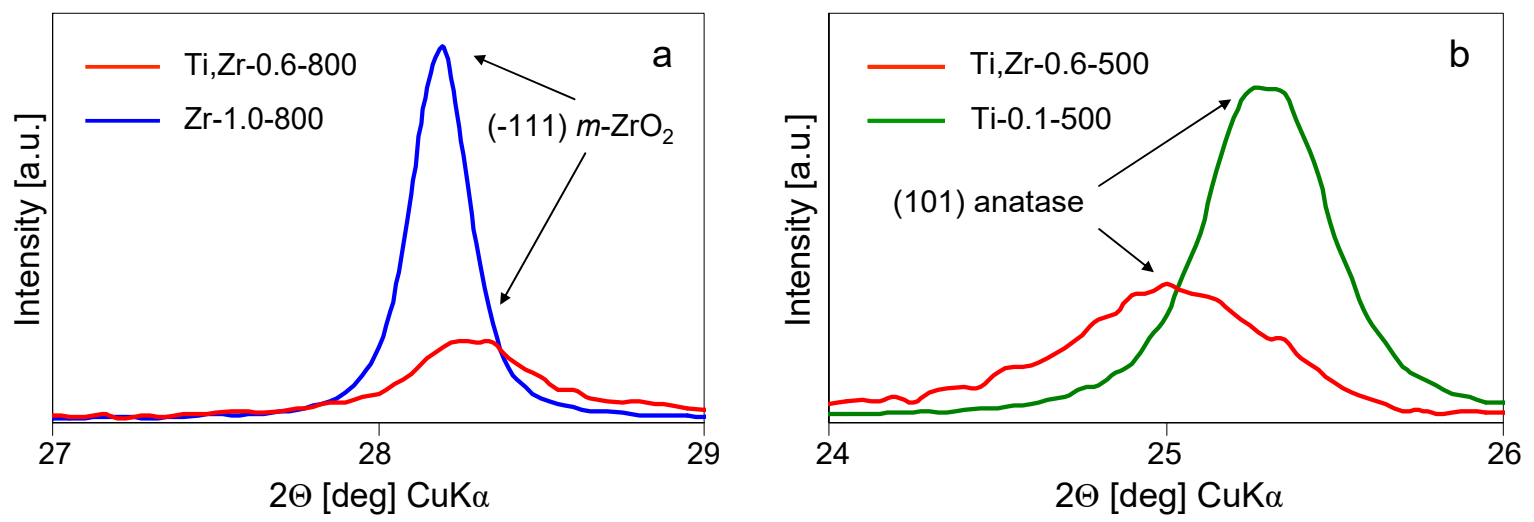

Figure 7. (a) Shift of (-111) XRD reflection of $m-\mathrm{ZrO}_{2}$ to higher $2 \Theta$ in multiphase $\mathrm{Ti}, \mathrm{Zr}-0.6-800$ with respect to its position in Zr-1.0-800, (b) shift of (101) XRD reflection of anatase to lower $2 \Theta$ in multiphase $\mathrm{Ti}, \mathrm{Zr}-0.6-500$ with respect to its position in Ti-0.1-500.

XRD patterns of solids obtained from pillaring solution whose $\mathrm{pH}$ was adjusted to 1.2 with ammonia addition (Figure $6 \mathrm{~b}$ ), reveal a completely different nature of lyophilized Ti, Zr-1.2 precipitate and of products of its thermal treatment at 500,800 and $1000^{\circ} \mathrm{C}$. Apart from the sharp reflections, due to formation of some $\mathrm{NH}_{4} \mathrm{Cl}$, the Ti, $\mathrm{Zr}-1.2$ precursor has a quasi-amorphous character. The broad peak at $2 \Theta \approx 5.9^{\circ}(\mathrm{d} \approx 15.0 \AA)$ points to the nucleation of a layered type of structure, whose other feature is an elevated background around $2 \Theta \approx 28^{\circ}(\mathrm{d} \approx 3.2 \AA)$. In $\mathrm{Ti}, \mathrm{Zr}-1.2-500$ the low $2 \Theta$ reflection disappears, but the sample is still strongly amorphous, except for two peaks emerging from the broadly elevated background, assignable to the most intense reflections of $\mathrm{ZrTiO}_{4}$. Full set of reflections characteristic of zirconium titanate becomes visible after calcination at 800 and $1000{ }^{\circ} \mathrm{C}$. Thus, in contrast to the multiphase nature of solids evolving from $\mathrm{Ti}, \mathrm{Zr}-0.6$ sample, $\mathrm{ZrTiO}_{4}$ is the only phase crystallizing from the quasi-amorphous Ti, $\mathrm{Zr}-1.2$ precipitate.

The Raman spectra of Ti, Zr-0.6 and Ti, Zr-1.2 series of samples are gathered in Figure $8 a, b$, respectively. The spectrum of lyophilized $\mathrm{Ti}, \mathrm{Zr}-0.6$ precipitate shows only very weak, broad bands. The features around 440 and $590 \mathrm{~cm}^{-1}$ may be attributed to zirconyl chloride hydrates, whose presence has been identified by XRD, the other, around 160,250 , and $830 \mathrm{~cm}^{-1}$, are assigned to the quasi-amorphous layered structure. It is likely that the amorphous phase contains both $\mathrm{Ti}$ and $\mathrm{Zr}$, because the band at ca. $830 \mathrm{~cm}^{-1}$ has been previously attributed to the formation of Ti-O-Zr in amorphous $\mathrm{Zr}$-rich oxide-like material [29]. The Raman spectra of Ti, $\mathrm{Zr}-0.6$ sample calcined at 500, 800 and $1000{ }^{\circ} \mathrm{C}$ confirm the XRD findings as to the multiphase nature of these solids (Figure 8a).

Thus, after thermal treatment at $500{ }^{\circ} \mathrm{C}$, the Ti, Zr-0.6-500 sample shows several bands, of which the ones at 143, 406, 515 and 642 may be attributed to anatase. Formation of zirconium titanate component is also documented by Raman spectrum. According to literature, the most intense Raman bands of this phase are found at $\sim 160, \sim 275, \sim 340, \sim 410, \sim 640$, and $\sim 790 \mathrm{~cm}^{-1}$, weaker ones at $\sim 540$, $590 \mathrm{~cm}^{-1}$ [12,29-33]. The bands tend to be quite broad, which has been attributed to the random distribution of $\mathrm{Zr}$ and $\mathrm{Ti}$ atoms at equivalent structural positions, combined with anionic defects and/or minor variation of stoichiometry in polycrystalline materials [29,34]. The bands around 275 and $785 \mathrm{~cm}^{-1}$ may be taken as diagnostic for this compound, as they do not overlap with vibrations stemming from other phases. The $\mathrm{ZrTiO}_{4}$ modes at 410 and $640 \mathrm{~cm}^{-1}$ contribute to the intensity of 406 and $642 \mathrm{~cm}^{-1}$ maximum. The shoulder at $170 \mathrm{~cm}^{-1}$ may also be attributed to $\mathrm{ZrTiO}_{4}$. However, no Raman bands of monoclinic $\mathrm{ZrO}_{2}$, whose presence is documented by XRD, can be detected, even in the spectral ranges where no overlap is expected (e.g., lack of feature around $475 \mathrm{~cm}^{-1}$, very strong in $\left.m-\mathrm{ZrO}_{2}\right)$. As demonstrated by Livraghi, et al. [35], the scattering properties of $\mathrm{ZrO}_{2}$ are 
much poorer than those of anatase, hence its bands are easily obscured in the systems containing both components. After calcination at 800 and $1000{ }^{\circ} \mathrm{C}$ the overall character of the Raman spectra is preserved, except that the main features become more pronounced, due to the better crystalline order of the sample components. Noteworthy, the $\sim 140 \mathrm{~cm}^{-1}$ band of anatase is also the strongest on the spectrogram of a sample calcined at $1000^{\circ} \mathrm{C}$, where, as evidenced by X-ray data, most of the anatase has been transformed into rutile, which confirms the exceptionally strong scattering properties of this modification of titania. For the same reason no rutile bands can be clearly distinguished in the spectrum of Ti, Zr-0.6-1000, even the least overlapping mode around $450 \mathrm{~cm}^{-1}$.
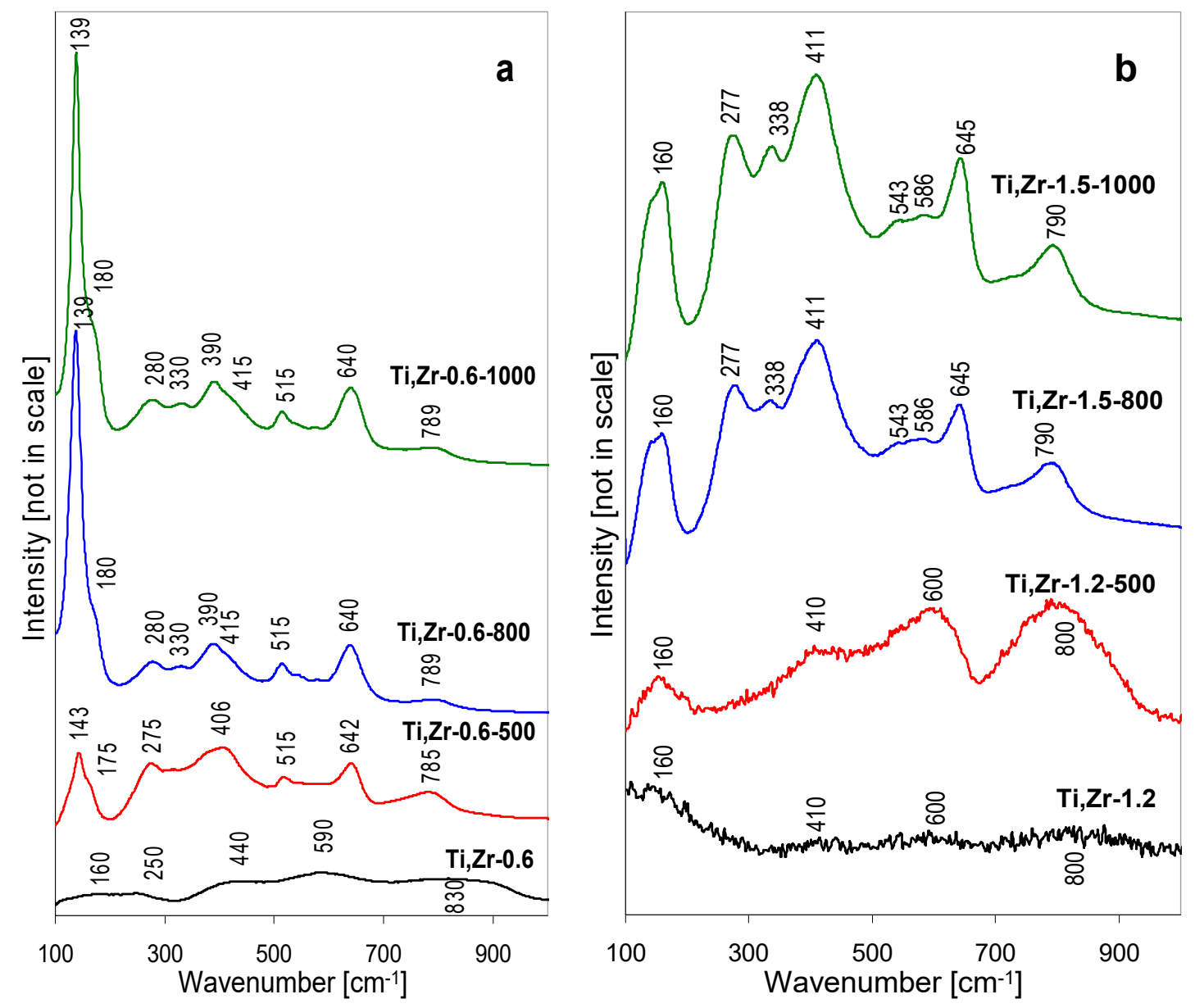

Figure 8. Raman spectra illustrating the effect of thermal treatment on hydrolysates obtained by lyophilization of $\mathrm{Ti}$, Zr-pillaring solution: (a) As received at $\mathrm{pH}=0.6$, (b) after $\mathrm{pH}$ adjustment to 1.2.

Raman spectra of samples obtained from titanium-zirconium pillared solutions with $\mathrm{pH}$ raised to 1.2 , i.e., the value observed during pillaring of montmorillonite, are different (Figure 8b). The spectrum of the lyophilized $\mathrm{Ti}, \mathrm{Zr}-1.2$ precipitate is poorly resolved, showing, similarly to other thermally untreated materials, only very broad bands, barely elevated from the background, at ca. 160, 410, 600 and $800 \mathrm{~cm}^{-1}$. As in other materials whose $\mathrm{pH}$ has been adjusted with ammonia addition, the amount of $\mathrm{NH}_{4} \mathrm{Cl}$ formed in the precipitate is not sufficient to mark its presence in the Raman spectrum. Changes observed upon thermal treatment show a close relation between the ensuing spectra, as the bands do not disappear but gradually become better resolved to yield the spectrum characteristic of $\mathrm{ZrTiO}_{4}$. Thus, in the Ti, $\mathrm{Zr}-1.2-500$ sample the faint features visible in the spectrum of Ti, $\mathrm{Zr}-1.2$ become more intense, in accordance with the XRD data which show that in this material the crystallization of $\mathrm{ZrTiO}_{4}$ from amorphous phase has just begun. The Raman spectra of Ti, Zr-1.2-800 and Ti, Zr-1.2-1000 show the full set of bands expected for $\mathrm{ZrTiO}_{4}\left(160,277,338,411,543,586,645\right.$ and $\left.790 \mathrm{~cm}^{-1}\right)$. 
No bands that might indicate the presence of other oxide components are present, which confirms the single-phase nature of the material produced from Ti, Zr-1.2 precipitate. Moreover, the obvious kinship between the spectra is an indication that already in the thermally untreated quasi-amorphous precursor the short order interatomic bonding is closely related to that developed in the zirconium titanate.

SEM analysis of Ti, Zr-0.6-1000 and Ti, Zr-1.2-1000 samples reveals significant differences in morphology of both materials (Figure 3c,f, respectively). Thus, Ti, Zr-0.6-1000 is composed of grains with various shapes, ranging from small rounded particles to larger rectangular blocks. The inhomogeneous composition of $\mathrm{Ti}$, Zr-0.6 series has been independently confirmed by the results of scanning electron microscope/energy dispersive spectrometer (SEM/EDS) analysis. Backscattered electrons (BSE) imaging, which strongly depends on the atomic number of the scattering elements, has been employed for analysis of the samples. BSE images are particularly suitable for detecting areas of different composition because the sample components containing heavier elements appear brighter. An example of the BSE image of Ti, Zr-0.6-1000 is shown in Figure 9a. The polycrystalline material is clearly composed of areas of different contrast, indicating differences in chemical composition of various parts of the specimen. The EDS analysis confirms that brighter regions are zirconium-rich, while darker contain mainly titanium. On the other hand, EDS analysis of Ti, Zr-1.2-1000 sample shows that the material is essentially homogeneous as far as the chemical composition is concerned, and no meaningful fluctuations around the expected $\mathrm{Ti} / \mathrm{Zr}$ ratio equal 1 are observed (Figure $9 \mathrm{~b}$ ). The results support the conclusion drawn on the basis of the XRD and Raman data, that the mixed oxide material obtained from Ti, Zr-1.2 precursor is structurally and compositionally uniform.
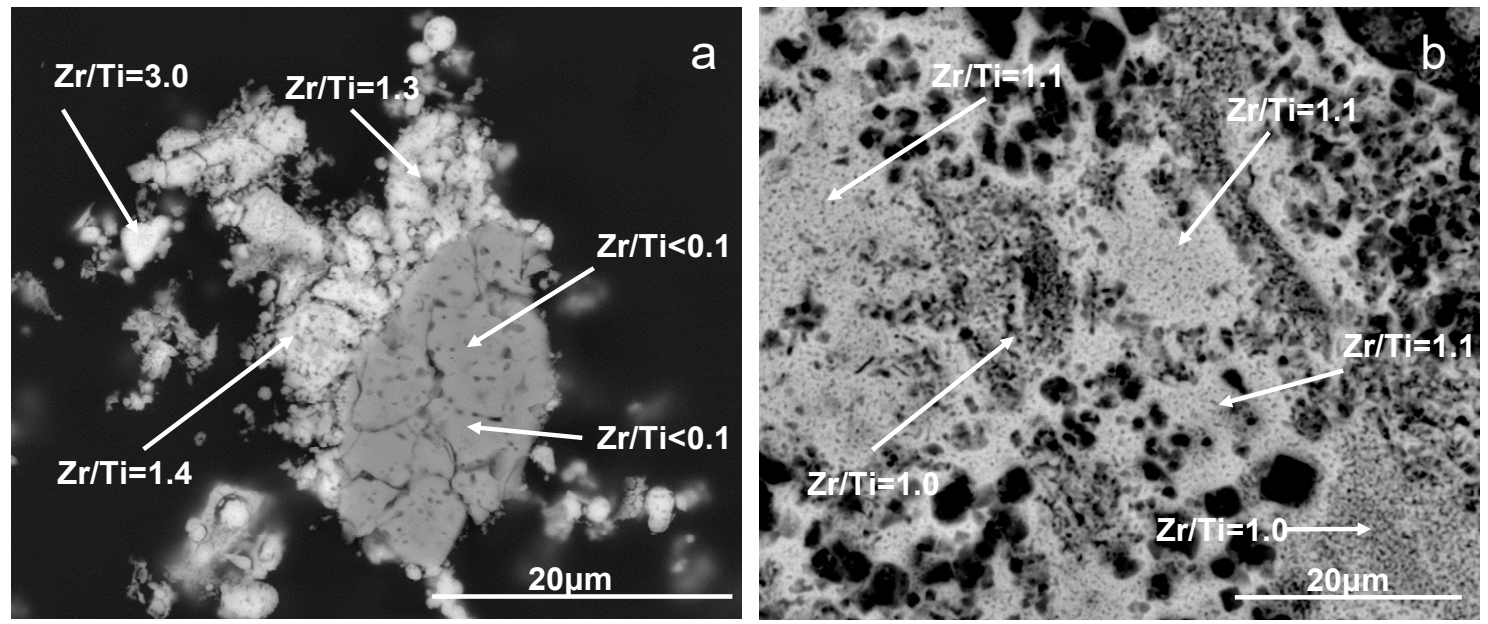

Figure 9. Scanning electron microscope (SEM) / Backscattered electrons (BSE) images of (a) Ti, Zr-0.6-500 and (b) Ti, Zr-1.2-500 samples. The Zr/Ti values found with EDS analysis for different areas of the samples are marked. Polished specimens of materials embedded in epoxy resin have been used for analysis.

Comparison of the data obtained for materials synthesized from mixed Ti, Zr-0.6 and Ti, Zr-1.2 precursors points to the critical influence of the $\mathrm{pH}$ of the solutions on the nature of mixed oxide materials derived from the lyophilized precipitates upon thermal treatment. For the former series an inhomogeneous polycrystalline material is produced, with the tendency to form, next to zirconium titanate, separate $\mathrm{Ti}$ - and $\mathrm{Zr}$-based phases. On the contrary, in the solids prepared from Ti, $\mathrm{Zr}-1.2$, the $\mathrm{ZrTiO}_{4}$ phase, accommodating both elements, is formed exclusively. Since the pH value of 1.2 has been selected to imitate the acidity generated during preparation of Ti, Zr-pillared montmorillonite, the results of the current experiments back the conclusion presented in our earlier work [2] that pillars possess a $\mathrm{TiZrO}_{4}$-like nature rather than constitute a mixture of titania and zirconia props. 


\section{Conclusions}

Results of the present study show that even a relatively moderate alteration of $\mathrm{pH}$ in $\mathrm{Ti}-, \mathrm{Zr}-$, or Ti, Zr-precursor solutions, such as that occurring during clay pillaring, brings about a substantial change in the outcome of hydrolytic transformations, manifested by different phase and/or chemical composition of hydrolysates recovered from these solutions. In particular, alkalization facilitates transformation of anatase into rutile in materials obtained from Ti-pillaring solution, but delays conversion of tetragonal to monoclinic zirconia in samples derived from Zr-pillaring agent. The most striking effect is observed for the mixed $\mathrm{Ti}, \mathrm{Zr}$-solution, where the increase of $\mathrm{pH}$ is the necessary condition for the formation of a single-phase material with mixed Ti-O-Zr network, rather than an inhomogeneous multiphase precipitate with the tendency to form separate Ti- and Zr-based phases obtained from the more acidic precursor. This finding indirectly supports the model of mixed titanium-zirconium props in pillared montmorillonites, and is an important indication for the design of Ti-Zr mixed oxide materials dedicated for other applications.

Author Contributions: K.B. conceived and designed the experiments, interpreted the results and wrote a draft of the paper, A.K. and A.M. synthesized the materials, A.K., A.G., K.G. performed the physic-chemical characterization experiments, E.S.-B. contributed to the interpretation of the results and prepared the final version of the manuscript.

Funding: This research was funded by the Polish National Science Center (NCN), grant OPUS 2017/25/ B/ST10/00768. A.M. and E.M.S. acknowledge partial financial support by the statutory research fund of ICSC PAS.

Conflicts of Interest: The authors declare no conflict of interest. The funders had no role in the design of the study; in the collection, analyses, or interpretation of data; in the writing of the manuscript, or in the decision to publish the results.

\section{References}

1. Vicente, M.A.; Gil, A.; Bergaya, F. Pillared Clays and Clay Minerals. In Handbook of Clay Science, 2nd ed.; Bergaya, F., Lagaly, G., Eds.; Elsevier: Amsterdam, The Netherlands, 2013; pp. 523-557, ISBN 978-0-08-098259-5.

2. Bahranowski, K.; Włodarczyk, W.; Wisła-Walsh, E.; Gaweł, A.; Matusik, J.; Klimek, A.; Gil, B.; Michalik-Zym, A.; Dula, R.; Socha, R.P.; Serwicka, E.M. [Ti, Zr]-pillared montmorillonite-A new quality with respect to Ti- and Zr-pillared clays. Micropor. Mesopor. Mater. 2015, 202, 155-164. [CrossRef]

3. Michalik-Zym, A.; Dula, R.; Duraczyńska, D.; Kryściak-Czerwenka, J.; Machej, T.; Socha, R.P.; Wlodarczyk, W.; Gaweł, A.; Matusik, J.; Bahranowski, K.; et al. Active, selective and robust Pd and/or Cr catalysts supported on Ti-, Zr- or [Ti, Zr]-pillared montmorillonites for destruction of chlorinated volatile organic compounds. Appl. Catal. B Environ. 2015, 174, 293-307. [CrossRef]

4. Das, D.; Mishra, H.K.; Parida, K.M.; Dalai, A.K. Preparation and characterisation of Zr, Ti and Zr-Ti mixed oxide pillared montmorillonite and their catalytic activity towards nitration of chlorobenzene. Ind. J. Chem. 2002, 41A, 2238-2243.

5. Houari, M.; Saidi, M.; Tabet, D.; Pichat, P.; Khalaf, H. The removal of 4-chlorophenol and dichloroacetic acid in water using Ti-, Zr-and Ti/Zr-pillared bentonites as photocatalyst. Am. J. Appl. Sci. 2005, 2, 1136-1140. [CrossRef]

6. Lin, Y.; Pi, P.; Yang, Z.; Wang, L. Synthesis and photocatalytic property of the $\mathrm{ZrO}_{2} / \mathrm{TiO}_{2}$ pillared laponite. J. Wuhan Univ. Technol. 2011, 26, 852-856. [CrossRef]

7. Henry, M.; Jolivet, J.P.; Livage, J. Aqueous Chemistry of Metal Cations: Hydrolysis, Condensation and Complexation. Struct. Bonding 1992, 77, 155-206. [CrossRef]

8. Reddy, B.M.; Khan, A. Recent Advances on $\mathrm{TiO}_{2}-\mathrm{ZrO}_{2}$ Mixed Oxides as Catalysts and Catalyst Supports. Catal. Rev. Sci. Eng. 2005, 47, 257-296. [CrossRef]

9. Polliotto, V.; Albanese, E.; Livraghi, S.; Indyka, P.; Sojka, Z.; Pacchioni, G.; Giamello, G. Fifty-Fifty Zr-Ti Solid Solution with a $\mathrm{TiO}_{2}$-Type Structure: Electronic Structure and Photochemical Properties of Zirconium Titanate $\mathrm{ZrTiO}_{4}$. J. Phys. Chem. C 2017, 121, 5487-5497. [CrossRef]

10. Liang, L.; Sheng, Y.; Xu, Y.; Wu, D.; Sun, Y. Optical properties of sol-gel derived $\mathrm{ZrO}_{2}-\mathrm{TiO}_{2}$ composite films. Thin Solid Films 2007, 515, 7765-7771. [CrossRef] 
11. López-López, E.; Baudín, C.; Moreno, R.; Santacruz, I.; Leon-Reina, L.; Aranda, M.A.G. Structural characterization of bulk $\mathrm{ZrTiO}_{4}$ and its potential for thermal shock applications. J. Eur. Ceram. Soc. 2012, 32, 299-306. [CrossRef]

12. George, A.; Solomon, S.; Thomas, J.K.; John, A. Characterizations and electrical properties of $\mathrm{ZrTiO}_{4}$ ceramic. Mater. Res. Bull. 2012, 47, 3141-3147. [CrossRef]

13. Yuan, H.; Besselink, R.; Liao, Z.; ten Elshof, J.E. The swelling transition of lepidocrocite-type protonated layered titanates into anatase under hydrothermal treatment. Sci. Rep. 2014, 4, 4584. [CrossRef] [PubMed]

14. Gouadec, G.; Colomban, P. Raman Spectroscopy of nanomaterials: How spectra relate to disorder, particle size and mechanical properties. Prog. Cryst. Growth Charact. Mater. 2007, 53, 1-56. [CrossRef]

15. Balachandran, U.; Eror, N.G. Raman Spectra of Titanium Dioxide. J. Sol. State Chem. 1982, 42, $276-282$. [CrossRef]

16. Lottici, P.P.; Bersani, D.; Braghini, M.; Montenero, A. Raman scattering characterization of gel-derived titania glass. J. Mater. Sci. 1993, 28, 177-183. [CrossRef]

17. Tompsett, G.A.; Bowmaker, G.A.; Cooney, R.P.; Metson, J.B.; Rodgers, K.A.; Seakins, J.M. The Raman spectrum of brookite, $\mathrm{TiO}_{2}$ (Pbca, $\mathrm{Z}=8$ ). J. Raman Spectrosc. 1995, 26, 57-62. [CrossRef]

18. Gao, T.; Fjellvåg, H.; Norby, P. Raman Scattering Properties of a Protonic Titanate $\mathrm{H}_{\mathrm{x}} \mathrm{Ti}_{2-\mathrm{x} / 4} \square_{\mathrm{x} / 4} \mathrm{O}_{4} \cdot \mathrm{H}_{2} \mathrm{O}$ $(\square$, vacancy; $x=0.7)$ with Lepidocrocite-Type Layered Structure. J. Phys. Chem. B 2008, 112, 9400-9405. [CrossRef] [PubMed]

19. Pottier, A.; Chanéac, C.; Tronc, E.; Mazerolles, L.; Jolivet, J.P. Synthesis of brookite $\mathrm{TiO}_{2}$ nanoparticles by thermolysis of $\mathrm{TiCl}_{4}$ in strongly acidic aqueous media. J. Mater. Chem. 2001, 11, 1116-1121. [CrossRef]

20. Matsui, K.; Ohgai, M. Formation Mechanism of Hydrous Zirconia Particles Produced by Hydrolysis of $\mathrm{ZrOCl}_{2}$ Solutions: IV, Effects of $\mathrm{ZrOCl}_{2}$ Concentration and Reaction Temperature. J. Am. Ceram. Soc. 2002, 85, 545-553. [CrossRef]

21. Keramidas, V.G.; White, W.B. Raman Scattering Study of the Crystallization and Phase Transformations of $\mathrm{ZrO}_{2}$. J. Am. Ceram. Soc. 1974, 57, 22-24. [CrossRef]

22. Xie, S.; Iglesia, E.; Bell, A.T. Water-Assisted Tetragonal-to-Monoclinic Phase Transformation of $\mathrm{ZrO}_{2}$ at Low Temperatures. Chem. Mater. 2000, 12, 2442-2447. [CrossRef]

23. Dou, X.; Mohan, D.; Pittman, C.U.; Yang, S. Remediating fluoride from water using hydrous zirconium oxide. Chem. Eng. J. 2012, 198-199, 236-245. [CrossRef]

24. Barberis, P.; Merle-Méjean, T.; Quintard, P. On Raman spectroscopy of zirconium oxide films. J. Nucl. Mater. 1997, 246, 232-243. [CrossRef]

25. Teng, L.D.; Li, W.C.; Wang, F.M. Effect of Ti content on the martensitic transformation in zirconia for Ti-ZrO composites. J. Alloy Compd. 2001, 319, 228-232. [CrossRef]

26. Venkatachalam, N.; Palanichamy, M.; Arabindoo, B.; Murugesan, V. Enhanced photocatalytic degradation of 4-chlorophenol by $\mathrm{Zr}^{4+}$ doped nano $\mathrm{TiO}_{2}$. J. Mol. Catal. A 2007, 266, 158-165. [CrossRef]

27. Bineesh, K.V.; Kim, D.K.; Park, D.W. Synthesis and characterization of zirconium-doped mesoporous nano-crystalline $\mathrm{TiO}_{2}$. Nanoscale 2010, 2, 1222-1228. [CrossRef]

28. Wang, J.; Yu, Y.; Li, S.; Guo, L.; Wang, E.; Cao, Y. Doping behavior of $\mathrm{Zr}^{4+}$-doped $\mathrm{TiO}_{2}$ nanoparticles. J. Phys. Chem. C 2013, 117, 27120-27126. [CrossRef]

29. Krebs, M.A.; Condrate, R.A. A Raman spectral characterization of various crystalline mixtures in the $\mathrm{ZrO}_{2}-\mathrm{TiO}_{2}$ and $\mathrm{HfO}_{2}-\mathrm{TiO}_{2}$ systems. J. Mater. Sci. Lett. 1988, 7, 1327-1330. [CrossRef]

30. Chen, H.R.; Shi, J.L.; Zhang, W.H.; Ruan, M.L.; Yan, D.S. Incorporation of Titanium into the Inorganic Wall of Ordered Porous Zirconium Oxide via Direct Synthesis. Chem. Mater. 2001, 13, 1035-1040. [CrossRef]

31. Bordet, P.; McHale, A.; Santoro, A.; Roth, R.S. Powder neutron diffraction study of $\mathrm{ZrTiO}_{4}, \mathrm{Zr}_{5} \mathrm{Ti}_{7} \mathrm{O}_{24}$, and $\mathrm{FeNb}_{2} \mathrm{O}_{6}$. J. Solid State Chem. 1986, 64, 30-46. [CrossRef]

32. Oanh, L.M.; Do, D.B.; Hung, N.M.; Thang, D.V.; Phuong, D.T.; Ha, D.T.; Minh, N.V. Formation of crystal structure of zirconium titanate $\mathrm{ZrTiO}_{4}$ powders prepared by sol-gel method. J. Electron. Mater. 2016, 45, 2553-2558. [CrossRef]

33. Azough, F.; Freer, R.; Petzelt, J. A Raman spectral characterization of ceramics in the system $\mathrm{ZrO}_{2}-\mathrm{TiO}_{2}$. J. Mater. Sci. 1993, 28, 2273-2276. [CrossRef] 
34. de Lucena, D.R.; Leite, E.R.; Pontes, F.M.; Longo, E.; Pizano, P.S.; Varela, J.A. Photo luminescence: A probe for short, medium and long-range self-organization order in $\mathrm{ZrTiO}_{4}$ oxide. J. Solid State Chem. 2006, 179, 3997-4002. [CrossRef]

35. Livraghi, S.; Olivero, F.; Paganini, M.C.; Giamello, E. Titanium Ions Dispersed into the $\mathrm{ZrO}_{2} \mathrm{Matrix}$ Spectroscopic Properties and Photoinduced Electron Transfer. J. Phys. Chem. C 2010, 114, 18553-18558. [CrossRef]

(c)

(C) 2018 by the authors. Licensee MDPI, Basel, Switzerland. This article is an open access article distributed under the terms and conditions of the Creative Commons Attribution (CC BY) license (http://creativecommons.org/licenses/by/4.0/). 